\title{
Functionality and artistic creativity in design of environmentally integrated architecture
}

\author{
A. Berezin \& B. V. Gonzalez \\ Department of Engineering Physics, McMaster University, Canada
}

\begin{abstract}
Architectural creativity almost invariably operates within the constraints of functionality, structural and material engineering codes, as well as a variety of environmental aspects which as a rule are highly specific for a particular architectural project. As a result, an eventual public perception and an assigned social value of a particular piece of architecture are formed on the basis of numerous parameters such as individual and group psychology, existing social frame of reference, dominant esthetic and artistic views as well as a variety of utilitarian ends. All these factors are highly interactive and subjected to complicated geographical, demographical and historical variations, not to mention a broad range of individual modes of reflection. This paper presents an overview of the above mentioned aspects under the angle of psychological, social and technological factors affecting the creativity of a designer of environmentally integrated architecture. We use analogies from natural sciences (self-organization, chaos theory, strange attractors, etc), as well as provide some historical and philosophical comments. Of our particular interest are unusual and surrealistic architectural solutions which are often in the focus of public and touristic interests.
\end{abstract}

Keywords: architecture, creativity, environment, environmental integration, public perception, self-organization, esthetics, surrealism.

\section{Introduction}

Human creativity as expressed in architecture is a multi-faceted phenomenon in which the artistic inspiration and imagination of creators are working in a complicated framework of numerous technological, social, economical, psychological, and (at times) political constrains. The objects of architecture, 
which in common language are often referred to as "real estate" by their very purpose and implementation, exist at a background of natural and/or built environment. Hence, the degree of integration, and the tensions this integration invokes, is subjected to (an often chaotic) evolution in time which as a rule changes upon the dynamics of social context.

This paper combines the views of two professionals. One is a theoretical physicist (AAB) whose recent work was in the area of quantum effects, nanotechnology and the theory of chaos in non-linear systems $[1,2]$. The other (BVG) is an architectural designer who is especially interested in environmentally integrated architectural solutions. We believe that such a blend gives us a common platform and a synthetic power for the interdisciplinary comments which follow below. The conceptual linkages and vistas which we propose herewith may be useful as stimuli for those interested in integration of architecture and environment.

In the present paper we do not provide any photographs of specific buildings since virtually all key illustrative material can nowadays be found on the Web through the search by the names of the architects or localities.

\section{Architecture within the dominant worldview}

In almost any review of architecture over the extensive period of time (e.g., [3, 4]) one can find comments relating architecture with the dominant world view ("Zeitgeist") of the society which produced them.

\subsection{Architectural styles and underlying forming factors}

Overview of architectural styles over the centuries and continents shows a great variety of such "architectural archetypes". Metaphysical and philosophical reflections on architecture are often encountered in arts, enough to recall such images as "Belvedere" (1958) by Maurits Escher (1989-1972) or "The Architect's Dream" (1840) by Thomas Cole (1801-1848).

\subsubsection{Canadian architectural styles}

As this article originates in Canada, we feel it is prudent and instructive to mention some architectural styles in this country. The authors of the compendium [5] identified the following styles: Quebec, Palladian, Neoclassical, Revival Gothic, Italianate, Second Empire, High Victorian, Romanesque, Chateau, Beaux-Art, Edwardian, Chicago, Art Deco, Modern, Tudor, Spanish Colonial, Prairie, Brutalist, Expressionist, Post-Modern (a few are omitted, and the authors [5] call this list just a sampling, not a complete catalogue). Since Canada is a relatively new country, such a long tapestry of architectural styles seems to us quite impressive.

\subsubsection{Metaphysical factors}

In-spite that in broadly held common perception the architecture does not seem to have much to do with philosophy and metaphysics, the in-depth analysis reveals strong underlying links. Personal motivations of architects, as a rule, 
combine (in greatly varying proportions) business, career and material rewards interests and urges of creative self-expression. The latter are often controversial and socially provocative. Enough to recall the fact that soon after the construction of the Eiffel Tower for the Paris World Fair of 1889, there were strong voices demanding to dismantle it as an "eyesore" and an "insult" to Paris. Angry voices came from such key figures of French culture as writers Alexandre Dumas and Guy de Maupassant, composer Charles Gounod, painter Ernest Meissonier, etc. Yet, this "ugly scrap of metal" soon to take its well deserved place among the top universally admired architectural world landmarks, which, among other things, excellently fits its "environment". This (and many other) examples show that the individual and collective perception and a whole gamut of human emotions often offsets the pragmatic and material aspects of architecture. Thus, talking of non-material aspects and impacts of architecture, it appears appropriate to label them as "metaphysical factors", as some other authors apply this term [3].

2.1.2.1 Architectural Platonism is at length discussed by Charles Jencks [3], who associates it with some top names (Le Corbusier, Mies van der Rohe, Walter Gropius, etc). Within Platonic paradigm buildings represent some underlying cosmic order. As a norm, architects aspire their creations to last well beyond their individual lifetimes. Hence, the "resonances with eternity" and "eternal values" can be traced in almost all great pieces of architecture, from Pyramids and Greek temples, to Gothic cathedrals and some best examples of modern architecture. As a visionary architect Santiago Calatrava puts it, The artist or the architect can send his message across time by very force of form and shadow ([6], p. 9).

2.1.2.2 Information theory and its interpretive framework gives an efficient tool to attribute to the architectural inspirations the role of the actual driving forces of conceiving and implementing a specific architectural project. The work of a prime designer (which now for the most part proceeds as CAD - Computer Automated Design modelling) purports to convert the digital "bits and bytes" into an eventual material construct. Thus, information as a "negative entropy" [7] acts as facilitator (or a catalyser) of a self-organization and complexity emergence of the end product (e.g., a building or an architectural complex).

\section{Architecture in a diversity of human perceptions}

The above quoted example of the controversial public acceptance of Eiffel Tower is common to many great and impactful pieces of architecture. While in arts and architecture (as in most other creative activities) quantitative assessment, such as ranking, are as a rule unreliable and often misleading, some general observations can, nonetheless, be suggested, at least hypothetically.

\section{1 "Natural" and "un-natural" traits in architecture}

Artistic expression of almost all kinds often include elements of randomness, unexpectedness and (what some call it) - weirdness. This is a common feature 
reflecting the inner human desire for self-expressing and creative originality. Numerous examples of that exist in virtually all types of creativity - visual arts, architecture, plastic and performing arts (ballet), music, literature, poetry, etc. Similar traits can be observed even in science and technology (e.g., "weird" ideas of people like Nicola Tesla or Buckminster Fuller) and in a pop culture of modern younger generation (e.g., a current widespread use of tattoos and piercings, innumerous wall graffiti, etc).

\subsubsection{Diversity of architectural constructs}

While the classical architectural styles from antiquity, middle ages, renaissance, baroque, neo-classicism, art Nuevo and art Deco to most recent downtown cubicles are discussed in numerous sources, here we focus attention on lessknown, "off-line" manifestations. These non-mainstream architectural objects sometime act as "evolutionary seeds" for further architectural developments and a broader acceptance and imitation.

\subsubsection{Conceptual tools of interactive architectural analysis}

Architecture, as other key forms of human creativity which are sustained over the entire history of civilization, can be analyzed along numerous lines of discourse. Here we would like to suggest a few glimpses relating various architectural phenomena with recently introduced concept of "meme" as well as ancient ideas of Platonism and more recent notion of archetypes. Furthermore, for some architectural complexes the degree of their integration with local and more distant environments become a significant factor in their public perception and popularity.

3.1.2.1 Architectural meme and Platonic archetypes may be suggested as specific extension of these concepts to the world of architecture. As all general concepts of this level, they allow for the rich interplay when applied to a concrete analysis of architectural activities and outcomes.

3.1.2.2 Concept of meme introduced by Richard Dawkins in 1976 [8] is an efficient working metaphor in discussing the propagation of almost anything, from fashions to popular current language idioms and house decorations. While the origin of this concept lies in the evolutionary biology as a vehicle for propagation of (generally useful) mutations, its use can be extended to many other areas [1], including dominant architectural styles. From physics standpoint the dynamics of the meme propagation has similarity with propagation of light waves according to Huygens Principle (each point of the light front becomes a source of the secondary emission). Our conceptual framework calls for the connection of these ideas to the notions of mathematical Platonism and Jungian archetypes.

3.1.2.3 Mathematical Platonism, although seemingly has little to do with architecture, is, nonetheless, often mentioned within the architectural discourse $[1,3,9]$. Strive to the ideal forms and proportions, such as Golden Mean [10], goes through the entire architectural history. Often claimed mathematical relationships in the Pyramids of Egypt (such as based on $p i=3.14159 \ldots$ number) 
always fall in this line. Imitations of these ancient pyramids are common in modern architecture, e.g., a new entrance to Louvre in Paris or a civil building in Quebec City are shaped in the same "platonic" form.

3.1.2.4 Jungian archetypes are presently a popular notion in various philosophical, psychological and metaphysical discourses. Originally proposed by Carl Gustav Jung (1875-1961), the usefulness and conceptual efficiency of this term comes from its capacity to connect and interlink various objects and phenomena into the common generic category. In this way, it has deeply rooted connections to such ideas as mathematical Platonism (ideal shapes and forms) and physical sciences (e.g., the theory of phase transitions when a small crystalline seed forces the crystallization of an extended sample into a particular crystal symmetry).

\subsubsection{Architectural genotypes and phenotypes}

While the above terms are primarily used in genetics, they can be transposed onto other areas where the growth and evolution dynamics can be traced. At a global scale architecture at large has aspects of growth, evolution and natural (perhaps, "quasi-Darwinian") selection. Here we confine our discussion to a few typological examples out of many more possible.

3.1.3.1 Dull and mediocre buildings are what most people perceive about the absolute majority of what is built in our cities and villages. At a superficial glance almost all building are "nothing special". At the exception of a small subset of truly remarkable buildings and architectural landmarks, all the rest appears as a pretty ordinary. But like with people (most people - at a superficial view - are "nothing special"), such a view is largely "in the eyes of the beholder". In fact, all people have their unique individuality and almost everyone can reveal some originality and be interesting in one way or another (we do not assign any values or ethical judgments here). Even serial residential dwellings, like townhouses, sometime exhibit a few "makeup" features to distinguish them from the rest (e.g., outside gardening, lawn sculptures, etc).

\subsubsection{Surrealism in architecture}

Like most artistic and architectural trends, surrealism exists in specific artifacts (paintings, buildings, etc) as well as a form of a general philosophical and metaphysical vision. In its best manifestations it is highly thought provocative and intellectually stimulating. Sometime, it calls for a careful balancing and compromises with functionality and practicality.

3.1.4.1 "Crazy" buildings, or buildings containing "crazy" or "weird" elements, are another relatively common phenomenon to attract the attention of common viewers and tourists. The degree of creativity in these features vary broadly, from such top masterpieces as buildings by Antony Gaudi or Frank Gehry, to some occasional "weird" elements in ordinary communal and residential buildings (e.g., floating stairs, humorous murals, etc). Public reaction to such buildings usually vary in broad ranges from admiration and excitement to charges in 
"architectural hooliganism" and alike. The above story of extreme emotions and diverse public feelings after the construction of the Eiffel Tower comes to mind.

3.1.4.2 Art and Design related buildings are especially suitable for the surrealistic implementations. Among many such "crazy" pieces of architecture amply scattered across the world, we mention here two examples located in Toronto, Canada. One is a new addition to Royal Ontario Museum known as Michael Lee-Chin Crystal (2007, architect Daniel Libeskind) and Ontario College of Art and Design (Sharp Centre for Design, 2004, architect William Alsop). The latter is a structure in which the functional cubicle (the actual building) stands on several intercrossing legs that invariably attracts public and touristic attention. Provocative, unconventional, whimsical, and perhaps irreverent, the building is remarkable in the context of Toronto. As a winner of a 2004 RIBA (Royal Institute of British Architects) Worldwide Award, the building was described as "courageous, bold and just a little insane."

3.1.4.3 Salvador Dali's house in Figueres, Catalonia, is a masterpiece of a surrealistic architecture with eye-catching arrangement of several "big eggs" placed along the roof of the building.

3.1.4.4 Randomness in architecture is another aspect of imaginative visionary thinking and design. There are numerous examples of the usefulness of randomness and random number generators in a variety of creative activities [11]. Random designs, subjected to technological and structural constrains, can open entirely new vistas of architectural creativity.

\subsection{Architecture as a value statement}

Some architects (for example, Daniel Libeskind) do not see architecture as just a creation of meaningful and functional objects, but also see it (architecture) as a vehicle and transmitter of powerful messages intended for the viewer. In this regard the building is loaded with a soul, a memory and a sense. For some ancient enigmatic constructions, when their very purpose is not obvious or disputable (e.g., Stonehenge in England, or "airstrips" in Peru) their environmental embedding significantly affects their popularity and touristic impact.

\subsubsection{Creativity and Imagination in Architecture}

History of architecture can be perceived through a dichotomy of canons and innovation. Robustness of established canons and architectural styles is in everlasting conflict with attempts to break them through innovative efforts, which often lead to radical and even "outrageous" architectural solutions. While similar conflicts exist in other creative endeavors, in architecture their specifics is colored by public functionality and expected durability of architectural constructs.

3.2.1.1 Originality and imitation, in architecture, as in any other creative activity includes technical, economical and social aspects. In this regard, architecture is bound to balance at the interface of the originality and imitation. 
However, the boundary between originality and imitation is often blurred and fuzzy and is subjected to a variety of individual interpretations.

3.2.1.2 Individualization of mass architecture such as "conveyor belt" buildings (e.g., scores of similar townhouses in cities and suburbs), is another issue where the actual owners often do some personal quasi-architectural developments such as gardening, front-yard sculptures, fountains, etc. To that may be added paintings on murals, occasional graffiti, etc. In spite that much of the graffiti can be seen as nuisance, occasionally some are artistically good and may bear meaningful public messages.

\subsubsection{Computer assisted design}

Almost all areas of modern technological and building design is nowadays heavily computerized. While in the over-all sense it is an unquestionable benefit for the designers, it also opens up a few psychological, and at-times ethical, issues. They all lie along the general quest of the computer-human interaction.

3.2.2.1 Human-computer symbiosis is the first issue here. As someone put it in a popular cliche, it is not so much a problem that the computers becomes like humans, but that humans becomes like computers. Virtual art and futurological architecture affects the mentality of creators in many ways with a need of careful checks and balancing of benefits and costs.

\subsection{Public validation}

Popularity of any product of human effort (consumer goods, arts, architecture, music, etc) is the main factor in its perceived social value. It forms through a complex interaction of pragmatic functionality, esthetic appeal, economic and market availability and claimed (or perceived) originality. In architectural implementation of buildings with focused social goals, from churches to downtown business skyscrapers, the expected perception of the viewer always has an implicit (and sometime explicit) presence. The viewer instinctively puzzled by the quest what kind of a message this construct bears, what the architect wanted to express through it. What kind of a message the Eiffel Towers bears? The Empire State Building? The Salvador Dali ("eggs") house? Is such a message contextually and historically dependent? Will it change with time? Is it the same for different people, or each one perceives it with broad individual variations? These, and many other, questions arise (often subconsciously) in the minds of people facing this-or-that architectural object.

\section{Architectural creativity and non-linear dynamics}

Modern non-linear dynamics and complexity theory provide versatile investigative tools, as well as powerful conceptual links and metaphors, for a broad range of processes happening in nature and in society. Capacity of providing unifying models for vastly different processes is the main strength of this methodology. This is where theoretical physics creatively meet day-to-day life issues from psychology, conflict resolutions and medical sciences to arts, 
humanities and architecture. In this Section we mention several specific examples in architectural design connotation.

\subsection{Architectural integration}

There are several aspects for the efficient and constructive contextual integration of the building(s) with the local environment. Ideally, truly integrated architectural constructs have to respect and reflect the history of the place, location, as well as short-range (and sometime long-range) surroundings. Yet, within the context of physical terminology, the process can be analyzed along several lines.

\subsubsection{Self-amplification process in architecture}

Similar to other dynamical processes, self-amplification in architectural creativity can be described as a resonance energy-exchange process when the mind and the creative capacity of a designer are feed-backed by nearly-similar existing constructs.

\subsubsection{Strange attractors as "ideal designs"}

In physics the concept of a strange attractor (to which the phase trajectory of a system tends to return) plays a key role in self-organization and complexity emergence. In a visionary architectural design this is an ideal virtual target to which the design-in-progress "strives" to. The fractal structure of a strange attractor allows the designer to fracture the design process onto separate fragments and stages. In modern practice it is often carried out though the subcontracting of various stages of complex architectural design to different companies.

\subsubsection{Light engineering in architecture}

There are many ways in which the light and lighting affects the perception and public validation of architecture. A few specific comments we put up here are:

4.1.3.1 Lighting of buildings and other architectural artifacts (fountains, monuments, etc) is a common practice across the world. It often goes with slowly varying colors to enrich human eyes reaction to different parts of the visible spectrum. Buildings become beacons of light. From night illumination of buildings in downtowns to Rainbow illumination of Niagara Falls, it invariably boosts the touristic value of these objects.

4.1.3.2 Natural illumination likewise contributes to the enhancement of the perceived esthetic value of architectural objects. Examples of that are shining churches at dusk (especially, when the location was carefully chosen, like many older churches and cathedrals), or such games of light as sun reflections on skyscrapers near sun-set - these often produce almost mysterious and spiritually rich feelings in viewers. 


\subsection{Architectural self-organization}

In this section we move further our examples of chaos theory towards some specific architectural styles and objects. In no way our examples should be seen as an exhaustive review, they, however, may be thought provoking for a search of other similar connections. Such ideas as pattern-forming fields (morphogenetic fields) [9] and such speculative offerings as morphic resonance by Rupert Sheldrake [12] can play a role in architectural creativity as in other creative areas.

\subsubsection{Cluster formation in Megacities}

Architectural development in cities is a highly interactive process with numerous connections to demographics, transportation, economics, business dynamics, etc. Much of these connections can be described as non-linear. One of obvious results of this is the formation of "clusters" of high-rise buildings (usually, a mixture of business, commercial and residential) in most large cities. A highlevel scope of cities like Toronto (say, from CN-Tower) immediately reveals several such clusters among largely green residential areas. This is an on-going trend which unstoppably spreads into surrounding areas.

\subsubsection{Scales of order in architecture}

Integration of smaller elements of architectural design with over-all project requires not only a proper technological matching, but also an ergonomic and esthetic balancing. Occasional "oddities" in this regard can shift the impression of the viewers towards some enduring "messages" the architects may have in mind. Like chimeras on old cathedrals, castles and newer pseudo-gothic buildings, such additions can enhance the psychological effect of the architecture in question.

4.2.2.1 Hexagonal patterning of some cities and townships, which often met in many cities, from ancient to modern ([3], p. 349), is another example of spontaneous ergonomic development. While for the most part it is not deliberately planned (hence "spontaneous") and may take many generations to develop, such patterning provides better access to amenities, easier growth, greater space saving and makes more environmental sense than, say, a rectangular patterning of type we see at Manhattan.

4.2.2.2 Fake elements in architecture are often added for similar reasons. Examples are wall paintings based on optical illusions [13] or ambiguously looking constructions [1] which invoke perceptional bistability and multistability.

\subsection{Future trends and singularity points in architectural context}

As almost any major human activity, architecture can be viewed at different scales of observation and perception. Like visual arts (paintings, sculpture, etc), architecture is composed from individual pieces (buildings, bridges, etc) with numerous examples of masterpieces and (much more numerous) trivia and imitations. Yet on larger scales (both in terms of time and space) we talk about dominant architectural styles, fads and fashions, and general trends. 


\subsubsection{Architecture as evolutionary process}

The plurality of architectural styles and versatility of architectural creativity points to some qualified analogy with biological evolution. While the classical Darwinian understanding of evolution as competition and survival of the fittest is nowadays somewhat broadened (not all "less-fitted" are getting extinct) the principles of structural and functional optimization under the changing external conditions remain in effect.

4.3.1.1 Law of "natural selection" in architecture is, therefore, needs to be broadened to include some "off-line" (but publicly appealing) examples of "crazy" architectural projects, some of which find scores of imitations and in some cases are becoming mainstream (like numerous versions of non-vertical walls of the buildings, or twisted buildings and tower structures). As often mentioned, some of the best pieces of art and architecture are the ones that break the rules.

4.3.1.2 Singularity events in evolution are common (e.g., the sudden appearance of new species) and similar examples exist in arts and architecture. Emergence of new forms is sometime a singularity-type reaction to old styles and fashions or a spontaneous burst of novelty. Examples like emergence of Impressionism or Art Deco fit this pattern.

4.3.1.3 Cosmic architecture is a novel term to reflect creative impulses which are often generated by the sharp turns ("singularity events") of history. This puts such architecture in the context of geo-cosmic connections and such ideas as noosphere (V. Vernadsky, P. Teilhard de Chardin). For example, a book by Frederic Chaubin [14] is a collection of 90 photographs of recent architecture from Russia and former republics of the Soviet Union. The set of strangely looking ("visionary") buildings represents a chaotic reflection to the sudden collapse of the seemingly monolithic political entity (USSR). In-spite of some synchronicity in times of their construction, these exotic buildings represent no particular school or style, yet for the most part became local landmarks.

\subsection{Hard and soft architecture}

In modern physical sciences, condensed matter physics is presented by two major streams, solid state physics and soft matter physics. The first relates to hard crystalline structures, the second to polymers, fluids and biological structures. In architecture, while absolute majority of building are "hard" structures, there is a recent trend to grant some buildings or other structures certain traits of flexibility and fluidity. In fact, softness provides better seismic and tornado protection than hard solid structures. This flexibility and softness can come in a form of curved shapes which produce the appearance of a "static motion" in the viewers, similar to the apparent motion in some artistic images [1, 13]. An example is a residential complex in Mississauga, Ontario nicknamed "Marilyn Monroe Towers" - twin buildings formed in a shape of a female and male torso, respectively. 


\subsubsection{Tower stabilization in engineering and architecture}

The issue of stabilization is primarily (but not exclusively) concerns tall building such as skyscrapers or other tower structures. Commercial and demographic factors lead to an increased proportion of such buildings in growing cities of the world. Both public buildings (business skyscrapers in downtowns) and residential towers (condominiums) are becoming more and more common and more and more tall.

4.4.1.1 Dynamic stabilization of tall structures addresses such concerns as high winds, tornados, and seismicity. Without discussing all the available solutions, we mention here the use of floating water in connected vessels to offset for the possible trembling and dampen the vibrations. An example is tall (610 meters with antenna) TV Tower with Rotating Restaurant in Guangzhou (Canton), China. The tower is strong enough to resist a magnitude- 8 earthquake and typhoons that might occur once every 100 years. Its stabilization features include connected tanks of water which can be redistributed depending on the current wind pressures. The swings up to 80 centimeters at the tower top are considered to be safe. Other stabilization devices, such as shifting heavy metal counterweights, are also often employed. The latter - in a somewhat allegorical way - may be reminiscent to a tale by Jonathan Swift (1667-1745) in his Gulliver Travels ([15], p. 155) of a flying island Laputa, whose motion and stabilization was attained by huge movable blocks of magnetic limestone.

\subsubsection{Energy aspects}

While the energy requirements and energy balance is outside the scope of this paper, we can notice two recent developments to this effect which may have some bearing on architectural design, especially of tall buildings. The first is the use of geothermal heating systems such as heat pumps to supplement traditional heating means. Some tall buildings in downtown Toronto use such systems. The other growing trend is the use of photovoltaic panels (solar cells) at the roofs and top parts of the buildings which to some degree affect the perception of the buildings.

\section{Conclusion}

In this paper we have proposed (reviewed) a few parallels between concepts of non-linear physics $[1,11,16]$ and the architecture as a form of creative art and at the same time as a major technological and social activity. A variety of interactive models of physics can provide working analogies for the optimization of the integration of architectural constructs and ensembles with the environment. Our list of possible physical analogies is in no way complete catalogue, but rather a somewhat subjective sampling. In actual architectural decisions (like in most creative endeavors) such logical tools as fuzzy logic and complexity theory [17] are often used in explicit or implicit way. Optimization algorithms like Travelling Salesman problem or variational principles (e.g., Fermat minimum principle or Maximum Entropy principle) can be used as well. Some familiarity with these ideas can bring new insights to both architects and architectural decision makers. 


\section{References}

[1] Berezin, A.A., "Archetypes of art and concepts of science as pathways from natural to engineering design", In Design and Nature V, WIT Transactions on Ecology and the Environment, vol. 138, Editors: A.Capri \& C.A.Brebbia, pp. 571-582, WIT Press, Southampton, Boston, 2010.

[2] Berezin, A.A., Gridin, V.V. and Yusim, O.V., "Air pollution in the context of Chaotic Dynamics and Quantum Physics Paradigms", In Ravage of the Planet III: Management of Natural Resources, Sustainable Development and Ecological Hazards, WIT Transactions on Ecology and the Environment, vol. 148, Editors: C.A. Brebbia and S.S. Zubir, pp.451-462, WIT Press, Southampton, Boston, 2011.

[3] Jencks, C., Modern Movements in Architecture, Second Edition, 1985, Penguin Books Ltd, Harmondsworth, Middlesex, England.

[4] Pevsner, N., The Sources of Modern Architecture and Design, 1969, Frederick A. Praeger, Inc., Publishers, New York, U.S.A.

[5] Maitland, L., Hucker, J. and Ricketts, S., A Guide to Canadian Architectural Styles, 1992, Broadview Press Ltd., Peterborough, Ontario, Canada.

[6] Jodidio, P., Santiago Calatrava, Architect, Engineer, Artist, Taschen $\mathrm{GmbH}$, Koln, 2007.

[7] Leff, H.S. and Rex, A.F., Maxwell Demon: Entropy, Information, Computing, 1990, Princeton University Press, Princeton, New Jersey.

[8] Dawkins, R., The Selfish Gene, Oxford University Press, 1976.

[9] Thompson, D.W., On Growth and Form, Dover reprint, 1942.

[10] Livio, M., The Golden Ratio: The Story of Phi, the World's Most Astonishing Number, Broadway Books, New York, 2002.

[11] Berezin, A.A., "Quantum aspects of self-organization in dynamically random systems", Dusty and Dirty Plasmas, Noise, and Chaos in Space and in the Laboratory, ed. H. Kikuchi, Plenum Press, New York \& London, pp.225-240, 1994.

[12] Sheldrake, R., Presence of the Past, Times Books, New York, 1988.

[13] Kitaoka, A. and Ashida, H, "Phenomenal Characteristics of the Peripheral Drift Illusion", Vision, Vol.15, No. 4, 261-262 (2003).

[14] Chaubin, F., Cosmic Communist Constructions Photographed, Taschen, 2011.

[15] Asimov, I., The Annotated Gulliver's Travels, Clarkson N. Potter, Inc. Publishers, New York, 1980.

[16] Casti, J.L., Searching for Certainty, William Morrow and Company, Inc., New York, 1990.

[17] Berezin, A.A. and Gridin, V.V., "Complexity theory in management of heritage architecture preservation", In Structural Studies, Repairs and Maintenance of Heritage Architecture XI (STREMAH 2009), WIT Transactions on The Built Environment, vol. 109, Editor: C.A.Brebbia, pp.255-266, WIT Press, Southampton, Boston, 2009. 